\title{
Simulation of Wind Generating Set Based on PID
}

\author{
Du Peidong ${ }^{1}$, Liu Fuchao ${ }^{1}$, Wang Xuchun ${ }^{2}$, Peng Jing ${ }^{1}$ \\ ${ }^{1}$ State Grid Gansu Electric Power Research Institute, Lanzhou, China \\ ${ }^{2}$ State Grid JinChang Electric Power Supply Company, Jinchang, China
}

Keywords: PID, wind generator set, simulation

\begin{abstract}
The pitch control strategy of the wind generator set in the paper applies power feedback closed loop control to implement that variable-speed constant-frequency wind turbine regulates constant power removal by adjusting pitch angle under the condition above the rated speed. The present output power of the generator is measured by power acquisition, and the power deviation is calculated out by comparing with the given power (the rated power of the generator). And the power variance is the input of the power controller. The controller sends the order of blade referring to pitch angle according to power variance, and the pitch-regulated mechanism adjusts the blade of the fan according to the pitch angle. The actual wind power generation system is a multivariable, nonlinear, strong coupling and time-varying complicated system, and it is difficult to establish the accurate mathematical model. So traditional PID algorithm is difficult to be qualified for the power controller of large high-performance wind generator set. The research indicates that parameter self-tuning PID controller based on fuzzy logic not only can solve the problem of linear control, but also adapts to nonlinear system [31]. Based on the basic rues of pitch control, the paper proposes a design scheme of fuzzy PID power controller, and simulates the wind generator set of fuzzy PID power controller.
\end{abstract}

\section{Introduction}

PID control. PID control is a traditional matured control mode. It is easy and effective, which makes it applied widely. And there has been integrated theoretical and technical level. However, PID parameters must be adjusted according to the controlled objects before applying PID control, and the accurate mathematical model of the controlled system should be known. When the controlled objects can't be accurately determined, or there is delay links, or the controlled objects change because of the temperature and component parameters, PID control can't achieve the expected control quality [32].

The conventional PID controller is a linear controller. It computes the deviation according to the given value and the actual output value. The proportion (P), integral (I) and differential (D) of the deviation is selected as the output of the controller and acts on the controlled objects.

The control rule in the time domain is

$$
u(t)=K_{P} \cdot\left[e(t)+\frac{1}{T_{I}} \cdot \int_{0}^{t} e(t) \cdot d t+T_{D} \cdot \frac{d e(t)}{d t}\right]
$$

The transfer function form is

$$
G(s)=\frac{U(s)}{E(s)}=K_{P} \cdot\left(1+\frac{1}{T_{I} \cdot s}+T_{D} \cdot s\right)=
$$

In the formula, $K_{P}$ is proportional coefficient, $T_{I}$ is integral time constant, and $e(t)$ is system deviation.

$$
e(t)=r(t)-y(t)
$$

In computer control system, digital PID controller is used, and the expression of control rule is

$$
u(k)=K_{P} \cdot e(k)+K_{I} \cdot \sum_{i=0}^{k} e(i)+K_{D} \cdot[e(k)-e(k-1)]
$$


In the formula, $e(i)$ is the deviation of the $\mathrm{i}$ sample, $K_{I}$ is integral coefficient and $K_{D}$ is differential coefficient.

The functions of the components of PID controller are as follows.

Proportional component: reflecting the deviation $e(t)$ of the system according to a certain proportion. Once there is deviation, the controller has the function of control at once to reduce the deviation. The greater the proportional coefficient $K_{P}$, the shorter the adjustment time of the system, the less the stable error. However, the greater $K_{P}$, the greater the overshoot, the more unstable the system.

Integral component: eliminating the steady state error of the system and improving the indifference degree of the system. The greater the integral coefficient $K_{I}$ is, the stronger the function of the integrals is, the smaller the steady state error, the shorter the adjustment time is. But the greater $K_{I}$ is, the worse the stability is.

Differentiation component: reflecting the variation tendency and rate of change of the deviation timely, and effectively improving dynamic performance of the system. It is general that the system overshoot reduces with the increase of integral coefficient $K_{D}$. However, if $K_{D}$ is greater, the system stability reduces.

\section{Fuzzy control}

In 1965, L.A.Zadch, the professor in University of California, firstly proposed the concept of membership function to describe the fuzzy set theory of fuzziness, which lays the foundation of fuzzy mathematics. The introduction of fuzzy set can directly express the judgment and the thinking process of the people with simple mathematical form, which not only makes the process meeting the fact and the thinking mode of the people possible, but also meets the urgent requirement of self-adapting to scientific development. Under the background, the fuzzy control theory emerges as an important application branch of fuzzy mathematics [33].

Automatic control field is widely applied by fuzzy mathematics. Fuzzy control has the incomparable advantages compared with other traditional control methods, so it becomes an important branch in control field. The advantages of applying fuzzy algorithm in domain field are as follows [34].

1) The applied language methods have not need to master accurate process mathematical model. The complicated production process is difficult to acquire the accurate mathematical model of operation process of the system, but language method can achieve the similarity.

2) The written fuzzy condition sentences are very easy to be added to the control link of the process.

3) For applying fuzzy control method, the dynamic quality of the process is evidently better than the conventional PID control. And it has greater adaptability to the change of process parameters.

\section{Fuzzy PID control}

In order to overcome the limitation of PID control and fuzzy control, and fully develops the advantages, the researchers proposes the concept of fuzzy PID control. Generally speaking, fuzzy PID can be divided into three types, fuzzy PID parameter self-adaptive control, fuzzy PID double-mode control and fuzzy PID compound control. Fuzzy PID parameter self-adaptive control selects deviation e and deviation change rate $\bar{e}$ as the input, and uses fuzzy control rule to modify PID parameter, for meeting the requirements of e and $\bar{e}$ for PID parameter self-adaptive in different times [36].

Fuzzy PID parameter self-adaptive finds out the fuzzy relationship of KP, KI and KD and $e, \bar{e}$. It modifies three parameters by continuously detecting $e$ and $\bar{e}$ according to fuzzy control principle to meet the requirement on control parameters in different times, which makes that the controlled objects have good dynamic and static performance. 


\section{Simulation of TD70s Wind Generator Set}

Wind generator set is a large inertia and nonlinear system. There are many parameters influencing wind generator set model. The establishment of the model is very complicated. The content includes aerodynamics, machinery and electric field. Limited by the actual conditions, the written model is difficult to describe the real wind generator system [40-42].

Garrad Hassan and partners Company has researched wind power for many years, and the research on wind generator set model is systematic and deep. So the developed GH Bladed is the internationally popular wind generator set simulation software, and the accuracy of the model has been verified by different wind generator sets in foreign wind generator enterprises. Therefore, the paper uses GH Bladed software to complete the simulation of pitch wind generator set. The main interface of the software is shown in Figure 1.

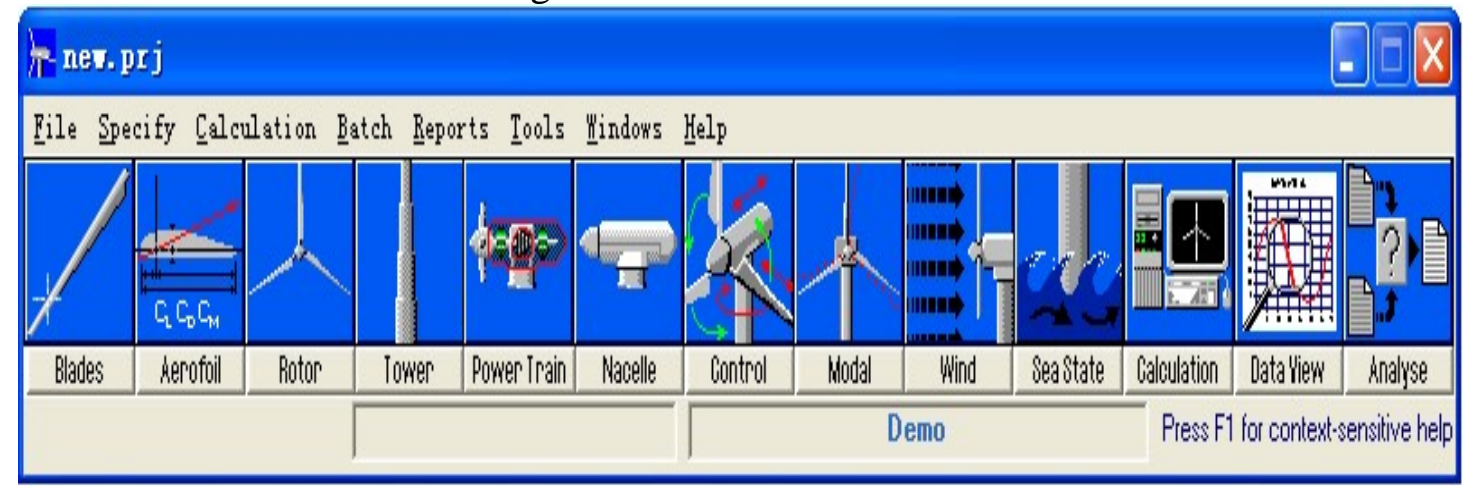

Figure 1 Main interface of GH Bladed software

GH Bladed simulation software completes structure design of wind generator set, wind speed signal simulation of wind field, control rule research, display and analysis of simulation process results.

\section{Simulation Results and Analysis}

After establishing the above model, the external conditions of the wind generator operation should be defined. When the fan operates under complicated natural conditions, the external conditions can be divided into normal external condition and extreme external condition. External condition includes all external conditions influencing fans such as landform and meteorological condition. After defining the external conditions of fan operation, the fans under different states can be simulated. Three simulation curves of fans under normal conditions are as follows. Figure shows that under the condition that the wind speed is less than $12 \mathrm{~m} / \mathrm{s}$, the curve of wind speed and pitch angle is shown in Figure 2(a), the rotor speed curve is shown in Figure 2(b), and the fan output power curve is shown in Figure 2(c). 


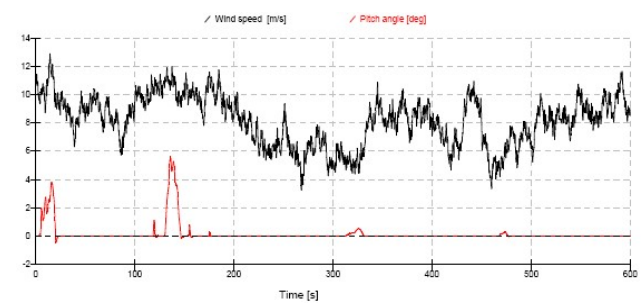

(a) Wind speed and pitch angle curve

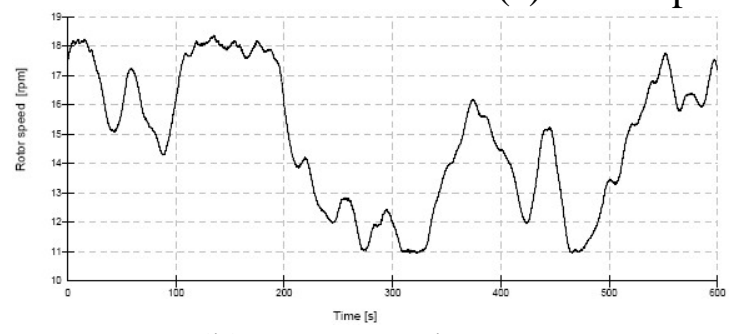

(b) rotor speed curve

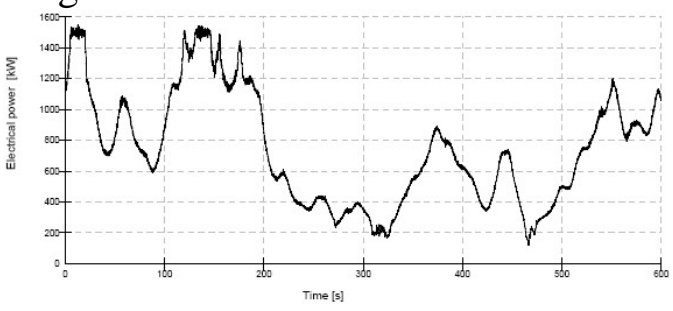

(c) Fan output power curve

Figure 2 Simulation results under low wind speed

Figure 3 shows the wind speed is near the rated wind speed $(12 \mathrm{~m} / \mathrm{s})$. The wind speed and pitch angle curve is shown in Figure 3(a), the rotor speed curve is shown in Figure 3(b), and the fan output power curve is shown in Figure 3(c).

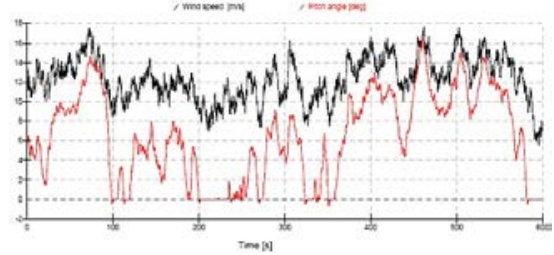

(a) Wind speed and pitch angle curve

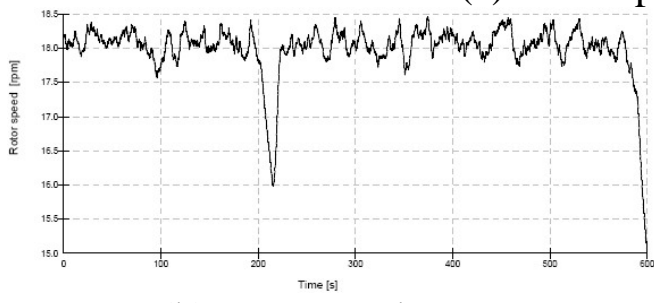

(b) rotor speed curve

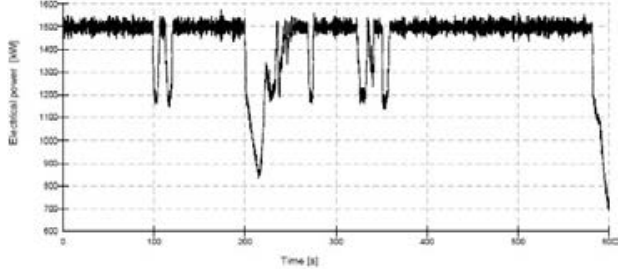

(c) Fan output power curve

Figure 3 Simulation results of wind speed section near the rated wind speed

Figure 4 shows that the wind speed is above the rated wind speed $(12 \mathrm{~m} / \mathrm{s})$. The wind speed and pitch angle curve is shown in Figure 4(a), the rotor speed curve is shown in Figure 4(b), and the fan output power curve is shown in Figure 4(c).

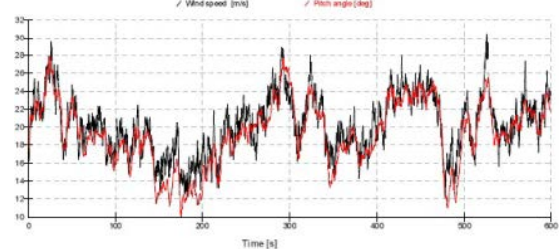

(a) Wind speed and pitch angle curve
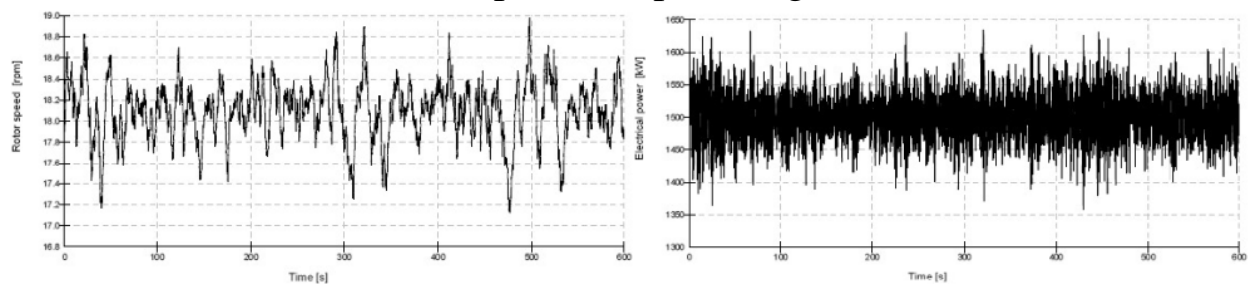

$\begin{array}{lll}\text { (b) rotor speed curve } & \text { (c) Fan output power curve }\end{array}$

Figure 4 Simulation results of high wind speed section 


\section{Conclusions}

For the multi-variable and great nonlinear characteristics of wind generator system, the paper firstly proposes a design scheme of fuzzy PID parameter self-adaptive power controller for wind generator set power feedback closed-loop control. Then, the paper simulates TD70s wind generator set in GH Bladed software, analyzes the simulation results and verifies the feasibility of the scheme in the paper.

\section{References}

[1] The Global Wind Energy Council. Global Wind Power Continues Expansion Pace of Installation Needs to Accelerate to Combat Climate Change. Wind Energy Conversion, 2008, (1):134-169.

[2] Dr Anil Kane. Global Wind Report 2007[R].Wind Energy Conversion, 2007, (1): 1-2.

[3] American Wind Energy Association. Global wind Energy Market Report. Wind Energy Conversion[R]. 2008, (3): 37-45. 